\title{
Female Feticide: A Mass Murder
}

\author{
Bhandari PM, ${ }^{1}$ Mishra SR ${ }^{2}$ \\ ${ }^{1}$ People's Health Movement Nepal Student's Circle (PHM-NSC) \\ ${ }^{2}$ Journal Office, Health Prospect, Volume 11
}

\section{Background}

More than a hundred million women are missing from this world because their parents wanted a son. (1) In our society discrimination against female prevails everywhere, even before birth. Female feticide is the intentional destruction of a fetus for the sole reason that it is female. The same fetus would have been granted life if it was a male. It is particularly widespread in India, Nepal, Bangladesh, Pakistan, China, South Korea, Singapore, and Taiwan. (2) In China its origins may be traced back to the first millennium. (2) Modern technologies, particularly the ultrasound machine, amniocentesis and trans-vaginal probes, have made it easier for parents and highly profitable for doctors to practice female feticide without any risk of detection and punitive legal action. (3) Medical technologies have played a crucial role in reinforcing the negative patriarchal systems that demand male heirs. It is the violation of a fundamental human right; the right to live.

The biological norm for birth ratio ranges from 102 to 106 boys born for every 100 girl worldwide. (4) But, in some regions of Asia this ratio has been distorted by a huge figure. According to the British medical journal, The Lancet (2006 January 9), over 10 million female fetuses (1 in every 25) have been aborted in India since 1994. In China, the imbalance between the sexes was 108 boys to 100 girls for the generation born in late 1980s; for the generation of the early 2000s, it was 124 to 1005 . The 1990 census of India showed that there were 25 million more males than females in India, (3) the government reacted by introducing a law making it illegal to detect the sex of a fetus through ultrasound examination (3). Yet by 2001, the gender gap had risen to 35 million3. In 2000, 138 boys were born for every 100 girls in the provinces of Jiangxi and Guangdong of China, which is $30 \%$ above the biological norm . (6)

Nepal, bounded by these two nations and having similar cultural preferences, the statistics shows a similar trend in some cities. UNICEF estimates that 20 percent of more than 70,000 abortions that take place in Nepal each year are carried out in preference for sons. (7) Abortion Law, legalized in 2002 in Nepal expressly prohibits sex determination and sexselective abortion. (8) Some ethnic groups and regions of the country, however, have skewed sex ratios favoring boys. (8)
A hospital-based review conducted in Patan, an urban area adjacent to Kathmandu, also found the sex ratio at birth to be skewed toward males (114 boys to 100 girls) during the 5year study period, 2003 to 20078 . The killing of girls in these countries means fewer wives and mothers in future generations to live, as a result, a significant increase in the imbalance of the number of men and women in the world can easily be predicted. (7)

The combination of relaxed laws and the availability of ultrasound technology have given tens of thousands of couple the opportunity to abort after knowing the sex of their fetus. (6) Sex-selective abortion remains illegal but the practice is quite common. The increase in rate of female feticide is a result of the greed and unethical practices of the medical community. The enforcement of the laws against female feticide is poor, with a very low rate of prosecution of offenders, including the medical practitioners, and extremely poor conviction rate.

\section{Underneath this practice of female feticide lie many reasons:}

Social and Economic Factors: Women in many rural areas are economically reliant on men who are traditionally the breadwinners which in turn impact the imbalance in the employment sector. (7) Modern desire of having a small family has blended with the advancement of technology to foster the rate of female feticide. People nowadays want 1 or 2 children, but only the males, which in-turn makes practice of feticide a common trend. Couples are ready to sacrifice their unborn daughters for the pursuit of sons. In Asian societies, social pressure is quite stronger than law. Females face inequality everywhere in these societies. Nowadays, some of them do not even get a chance to be born, live and to lead a healthy and productive life because of the trend of sexselective abortions.

The demographic dynamics of most of the Asian societies are likely to have severe repercussions because of the inherent and traditional bias against women. The son-centric model of our society forms the foundation of the practice of female feticide. Girls are made to face discrimination before birth, at birth and throughout their lives. The female child is increasingly seen as a high input and no output investment, 
reducing the child to little more than a commodity in the eyes of society. Even those girls who are allowed to live get secondclass treatment. They are denied adequate medical and health care facilities, adequate nutrition and educational facilities. They are often subjected to physical and sexual abuse. The females here are expected to find their salvation in marriage and service of the husband and family. Not only has the girl child been traditionally considered inferior to boys but also as a liability - a bride's dowry can financially cripple a poor family. Moreover, the dowry practice can deteriorate into a method of extortion of wealth from the bride's to the groom's parents, leaving many daughters' parents in debt and also taking the lives of girls in the name of dowry related violence (7)

The prevalence of female feticide has been found to be amazingly high in the families with greater economic status and higher educational level as they are the ones with easy access to this facility. (7).One study maps the increased frequency of female feticide with rising levels of education; lowest among women with a fifth-grade education and highest among women with university degrees. (9)

Cultural Factors: Most of the Asian societies have an age old fascination with the boy child. The culture here is profoundly patriarchal and the society is feudal where women aren't given any role in planning for their family. There is societal pressure for women to have male children and as a result women are often considered failures and tend to feel guilty after giving birth to a female child. (7) The cultural context, dominant Hindu religion, and patrilineal structure of our society confer high value and status to sons because they perform funeral rites, continue the family name, and bring resources into the family (wife and dowry) that help to support parents in old age. In these societies, people have the attitude that raising a daughter is like watering someone else's field. (2) Elderly parents traditionally can only depend on their sons while daughters end up joining another family and looking after the elderly people in that family. (7) In the Hindu religion, the son is responsible for lighting his parents' pyre, in order for them to reach Nirvana, and it is believed that having only girls in the family amounts to being condemned to a lower caste in the next world. (7)

Political Factor: One-Child Policy of China has fostered the prevalence of sex-selective abortions to a greater extent. Statistics of Gender Imbalance in Birth rate, Xinhua- 2006 July 12 , shows that there were 80 million one-child families and the son preference is particularly prevalent in rural areas, which has led to forced abortion.

\section{Consequences}

Female feticide not only denies the girl child her most basic human right - the right to be born - but it also turns women into silent victims. It has been found that mothers who have been put under pressure to kill their baby girls remain deeply hurt and injured for the rest of their lives as they cannot forget their own offspring. (7). They may be mentally traumatized after the feticide.

Over the next 20 years, in parts of China and India there will be a 12 to 15 percent excess of young men leading to an obvious bride shortage. (7) Between 2015 and 2030, there will be 25 million men in China who have no hope of finding a wife. (7) The social consequences will be more evident because the boys born in large numbers over the past decade will reach maturity then. Girls will get married at younger age. There will be substantial increase in organized crime. Low population of female can lead to the situation where all men of the family share the same wife. Women will be viewed as commodities and violence against women will flourish. UNICEF has warned that the alarming decline in the child sex-ratio is likely to result in more girls being married at a younger age, more girls dropping out of education, increased mortality as a result of early child bearing and an associate increase in acts of violence against girls and women such as rape, abduction, trafficking and forced polyandry. (7) Researchers have argued that an imbalanced sex ratio perpetuates gender discrimination against women, contributes to poor health in women, and disrupts social and familial networks. (8)

\section{Conclusion}

Achieving gender equality is one of the United Nation's Millennium Development Goals (MDGs) set for 2015, and every nation will have to address the issue of this heinous crime committed against female in the form of feticide, infanticide. Prenatal sex determination with the intention of preventing female births must be viewed as a manifestation of violence against women, a violation of their right to live. This trend of sex selection is extremely unhealthy and can have disastrous consequences for society. Moreover, a society which denies the girl child even the basic right to existence cannot claim to be civilized. A girl child has all the right to be born, to live, and to be loved. It is time for the government to take some serious steps to stop this serious act of crime against women by so called 'civilized' society. It is time for the women right activists to do some advocacy and bring awareness to this inhuman practice. Every responsible individual has to raise voice against this cold blooded murder.

Mitigation of this ill-practice will be possible only after empowerment of women and special focus on the humanist, scientific and rational approach. Strict ethical code for the doctors and acute monitoring the sale of ultrasound machines will surely aid in reduction of this malpractice. Punishment should be given to both parents who go for prenatal sex determination. There ought to be strict control over clinics that offer to identify the sex of a fetus and stronger check on abortions to ensure that they are not performed for the wrong reasons. Doctors must also be sensitized and strong punitive measures must be taken against those who violate the law. As the first point of contact for safe abortion care, providers should have significant role in banning sex selection and protecting women's health.Media can also play a significant 
role in elimination of traditional attitude which supports gender discrimination. Strict laws against female infanticide and dowry culture need to be formulated and implemented. Proper actions should be taken from the government's side to create an environment favorable for girls.

It will take generations to change people's mindset but the situation worldwide is so dramatic that we cannot afford to wait any longer. It is imperative that the international community calls on the governments and all actors responsible for this human and demographic tragedy to enact laws and take urgent measures to fight these violence and discrimination which, by denying the first basic right of all the right to life - denies all other human rights. We must march not only for an end to female feticide, but also to end all forms of violence against women. Everyone must respect women's rights and dignity from their birth till death as said by Mahatma Gandhi "Man and woman will attain equality only when the birth of a girl is celebrated with as much joy as in the case of a boy".

\section{References}

1. Amartya Sen, More Than 100 Million Women Missing. Available from: http://www.nybooks.com/articles/archives/1990/dec/20/ more-than-100-million-women-are-missing

2. Encyclopedia.com, [Accessed on: 2012 July 28] Available from: http://www.encyclopedia.com/article-1G2-3434600131/femaleinfanticide-and-fetal.html

3. Swami Agnivesh, Rama Mani and Angelika Kaster- Lossack. Missing: 50 million Indian girls. The New York Times, 2012 [updated on 2005, accessed on: 2012 July 9]. Available from: http://www.nytimes.com/2005/11/24/opinion/24ihtedswami.html

4. World Health Organization. Preventing gender-based sex selection: an interagency statement - OHCHR, UNFPA, UNICEF, UN Women and WHO. Geneva: World Health Organization; 2011

5. The Economist. The war on baby girls: Gendericide. [Accessed on: 2012 July 28] Available from: http://www.economist.com/ node/15606229

6. Tara Bhattarai. Sex-Selective Abortion on the Rise in Nepal. Global Press Institute, 2012 [Accessed on: 2012 July 10]. Available from: http://www.globalpressinstitute.org/global-news/asia/nepal/ sex-selective-abortion-rise-nepal

7. Working Group on the Girl Child. A Girl's Right To Live. NGO Committee on the Status of Women - Geneva; Conference of NGOs with Consultative Status with the United Nations (CONGO)

8. Lamichhane P, Harken T, Puri M, Darney PD, Blum M, Harper CC, et al. Sex-Selective Abortion in Nepal: A Qualitative Study of Health Workers' Perspectives. Women Health Issues. 2011 MayJun; 21(3 Suppl): S37-S41

9. Steven Ertelt. Nepal Sees Same Sex-Selection Abortion, Infanticide Problems as India. LifeNews.com [updated on: 2007 August 14, accessed on: 2012 July 9]. Available from: http:// www.lifenews.com/2007/08/14/int-381/ 